\title{
CFD Simulations to Study Parameters Affecting Gas Explosion Venting in Compressor Compartments
}

\author{
Kang Cen, ${ }^{1,2}$ Bin Song, ${ }^{1}$ Yan Huang, ${ }^{3}$ and Qingsheng Wang ${ }^{2}$ \\ ${ }^{1}$ School of Civil Engineering and Architecture, Southwest Petroleum University, Chengdu, Sichuan 610500, China \\ ${ }^{2}$ Department of Fire Protection \& Safety and Department of Chemical Engineering, Oklahoma State University, \\ Stillwater, OK 74078, USA \\ ${ }^{3}$ Panzhihua China Resources Gas Co., Ltd., Panzhihua, Sichuan 617000, China \\ Correspondence should be addressed to Kang Cen; 552129511@qq.com and Qingsheng Wang; qingsheng.wang@okstate.edu
}

Received 3 August 2017; Revised 5 November 2017; Accepted 13 November 2017; Published 11 December 2017

Academic Editor: Marco Pizzarelli

Copyright (C) 2017 Kang Cen et al. This is an open access article distributed under the Creative Commons Attribution License, which permits unrestricted use, distribution, and reproduction in any medium, provided the original work is properly cited.

In this work, a series of vented explosions in a typical compressor compartment are simulated using FLACS code to analyze the explosion venting characteristics. The effects of relevant parameters on the pressure peaks (i.e., overpressure and negative pressure) are also numerically investigated, including vent area ratio of the compressor compartment, vent activation pressure, mass per unit area of vent panels, and volume blockage ratio of obstacles. In addition, the orthogonal experiment design and improved grey relational analysis are implemented to evaluate the impact degree of these relevant parameters. The results show that the pressure peaks decrease with the increase of vent area ratio. There is an approximately linearly increasing relationship between the pressure peaks and the vent activation pressure. The pressure peaks increase with the mass per unit area of vent panels. The pressure peaks increase with the volume blockage ratio of obstacles. Based on the grey relational grade values, the effects of these relevant parameters on the overpressure peak are ranked as follows: volume blockage ratio of obstacles $>$ vent activation pressure $>$ vent area ratio $>$ mass per unit area of vent panels. These achievements provide effective guidance for the venting safety design of gas compressor compartments.

\section{Introduction}

Compressors are essential equipment in natural gas transportation and storage stations. Natural gas leakage would be easily caused by the high-frequency failure of compressors and associated piping [1]. Once there is a poor ventilation condition in compressor compartments, the accumulation of natural gas released might result in violent gas explosions, which would pose a great threat to operators' lives and public safety in the surroundings. Therefore, appropriate preventive and protective measures for mitigating the effects of gas explosions like venting, suppression, or containment must be taken properly [2]. Among all these measures, venting is widely used in gas compressor compartments to protect equipment and buildings against excessive pressure caused by an internal explosion, due to its advantages of low cost, ease of installation, and small occupation.

Numerous investigations regarding the explosion venting of combustible gas have been carried out to obtain optimal venting efficiency. For example, Liu et al. [3] investigated the characteristics of flame propagation and gas explosions in a $1.16 \mathrm{~m}^{3}$ explosion chamber with two circular quartz glass windows with a diameter of $20 \mathrm{~mm}$. Bauwens et al. [4] studied the effects of ignition location, vent size, and obstacles on vented explosion overpressure using stoichiometric propaneair mixtures in a $63.7 \mathrm{~m}^{3}$ vented vessel. Tomlin et al. [5] performed explosion venting experiments using natural gasair mixture with chemical equivalence ratio to analyze the effects of vent area and room congestion degree in a $182 \mathrm{~m}^{3}$ steel structure vessel. Fakandu et al. [6] investigated the effect of vent burst pressure on vented gas explosion pressure in a $10 \mathrm{~L}$ cylindrical vessel. Kasmani et al. [7] conducted explosion venting tests in a $0.2 \mathrm{~m}^{3}$ cylindrical vessel to investigate the effects of vent activation pressure and ignition location on the maximum overpressure and flame speed. $\mathrm{Pu}$ [8] conducted explosion venting tests to analyze the influences of dispersion-induced turbulence and obstacles on 
the flame propagation in vessels with volume and length-todiameter ratio varied. Höchst and Leuckel [9] carried out explosion tests using heavy venting devices and explosion doors to analyze the effect of the mass of venting devices in a $50 \mathrm{~m}^{3}$ silo. However, these efforts mainly focused on small spherical, cylindrical, and cubical vessels with volumes ranging from $0.009 \mathrm{~m}^{3}$ to $200 \mathrm{~m}^{3}$ [10]. Few of experiments of natural gas explosion in large-scale rectangular vessels such as compressor compartments have been carried out due to the high costs.

The empirical and semiempirical correlations derived experimentally have been developed to calculate the maximum overpressure inside a vessel during gas explosion processes. For instance, Cubbage and Simmonds [11, 12] developed one correlation that includes the effect of vent area coefficient on the explosion overpressure in cubical vessels with volumes varying from $0.23 \mathrm{~m}^{3}$ to $14.16 \mathrm{~m}^{3}$. Dragosavic [13] proposed a method that stresses the effect of vent activation pressure on the overpressure in vessels with volumes ranging from $20.8 \mathrm{~m}^{3}$ to $36 \mathrm{~m}^{3}$. Rasbash et al. [14] presented an equation that includes the effect of the mass of venting devices and laminar burning velocity of combustible mixture inside cylindrical and rectangular vessels with volumes varying from $0.009 \mathrm{~m}^{3}$ to $0.09 \mathrm{~m}^{3}$. Unfortunately, the above correlations do not contain information regarding the duration and the pressure-time history associated with an explosion, which may be essential for the venting design of an enclosure. Furthermore, these formulas are valid only within the given conditions covered by the specific experiments.

With the advancement of computer techniques and finite element analysis software, numerical simulation based on Computational Fluid Dynamics (CFD) has become one of the major methods to study the explosion venting process in large-scale confined spaces. For instance, Huser et al. [15] performed CFD simulations to analyze the effects of ignition location and vent area fraction on explosion overpressure in chemical process plants. Karnesky et al. [16] developed a three-dimensional gas dynamic model with constant burning velocity to analyze the effects of vent area and obstacles on explosion pressure in vented enclosures. Pedersen et al. [17] established CFD models to investigate the effects of vent size and flow interactions between two enclosures on the gas explosion venting process in a twin-compartment enclosure. These CFD models can provide more detailed and accurate results of a gas explosion process over a wide range of conditions and complex geometries than experimental tests and correlations alone.

Despite the fact that the extensive studies have been conducted in recent years, our understandings of how the venting process works still remain insufficient. In the venting design, the essential problem is to determine the vent area so that the explosion overpressure (i.e., the maximum reduced explosion overpressure $P_{\text {red }}$ ) does not exceed the maximum allowable overpressure of the enclosure. Currently, the two most widely applied explosion venting standards, namely, the American standard NFPA 68 [18] and European standard EN 14494 [19], have proposed engineering correlations to determine appropriate vent sizing. However, these standards may have their limitations due to the complex nature of the phenomena and the experimental data source, which were mainly measured in small- and medium-scale vessels. In addition, there are other influence factors for explosion overpressure such as vent activation pressure, mass per unit area of vent panel, and degree of obstruction. However, the relative importance of these influence factors has not been investigated quantitatively in the previous literature.

The objective of this research is to study the explosion venting characteristics inside gas compressor compartments using CFD simulation. The effects of relevant parameters on the pressure peaks (i.e., overpressure and negative pressure) are numerically investigated, including vent area ratio, vent activation pressure, mass per unit area of vent panels, and volume blockage ratio of obstacles. The orthogonal experiment design and improved grey relational analysis are implemented to evaluate the effects of these relevant parameters on the overpressure peak.

\section{Numerical Model}

2.1. Governing Equations. The explosion venting of combustible gas in the confined space is a complex and transient combustion process, which should satisfy the conservation equations for mass, momentum, enthalpy, and mass fraction of chemical species [20,21].

Mass conservation equation is

$$
\frac{\partial}{\partial t}\left(\beta_{v} \rho\right)+\frac{\partial}{\partial x_{j}}\left(\beta_{j} \rho u_{j}\right)=\frac{m}{V},
$$

where $\beta_{v}$ is the volume porosity; $\rho$ is the density; $\beta_{j}$ is the area porosity in the $j$ th direction; $u_{j}$ is the velocity component in the $j$ th direction; $m$ is the mass rate; and $V$ is the volume.

Momentum conservation equation is

$$
\begin{aligned}
\frac{\partial}{\partial t}\left(\beta_{v} \rho u_{i}\right)+\frac{\partial}{\partial x_{j}}\left(\beta_{j} \rho u_{i} u_{j}\right) \\
=-\beta_{v} \frac{\partial p}{\partial x_{i}}+\frac{\partial}{\partial x_{j}}\left(\beta_{j} \sigma_{i j}\right)+F_{o, i}+\beta_{v} F_{w, i} \\
+\beta_{v}\left(\rho-\rho_{0}\right) g_{i},
\end{aligned}
$$

where $p$ is the pressure; $\sigma_{i j}$ is the stress tensor; $g_{i}$ is the gravitational acceleration in the $i$ th direction; $F_{w, i}$ is the flow resistance due to walls; and $F_{o, i}$ is the flow resistance due to subgrid obstructions.

The flow resistance $F_{o, i}$ due to subgrid obstructions in (2) can be expressed as follows:

$$
F_{o, i}=-\rho\left|\frac{\partial \beta_{i}}{\partial x_{i}}\right| u_{i}\left|u_{i}\right| .
$$

Enthalpy conservation equation is

$$
\begin{aligned}
& \frac{\partial}{\partial t}\left(\beta_{v} \rho h\right)+\frac{\partial}{\partial x_{j}}\left(\beta_{j} \rho u_{j} h\right) \\
& =\frac{\partial}{\partial x_{j}}\left(\beta_{j} \frac{\mu_{\mathrm{eff}}}{\sigma_{h}} \frac{\partial h}{\partial x_{j}}\right)+\beta_{v} \frac{D p}{D t}+\frac{Q}{V},
\end{aligned}
$$


where $h$ is the enthalpy; $\mu_{\text {eff }}$ is the effective viscosity; $\sigma_{h}$ is the Prandtl-Schmidt number; typically $\sigma_{h}=0.7 ; Q$ is the heat transfer rate between the fluid and the internal obstructions in the volume.

Mass fraction of chemical species conservation equation is

$$
\begin{gathered}
\frac{\partial}{\partial t}\left(\beta_{v} \rho Y_{\text {fuel }}\right)+\frac{\partial}{\partial x_{j}}\left(\beta_{j} \rho u_{j} Y_{\text {fuel }}\right) \\
=\frac{\partial}{\partial x_{j}}\left(\beta_{j} \frac{\mu_{\text {eff }}}{\sigma_{\text {fuel }}} \frac{\partial Y_{\text {fuel }}}{\partial x_{j}}\right)+R_{\text {fuel }},
\end{gathered}
$$

where $Y_{\text {fuel }}$ is the mass fraction of a chemical species; $\sigma_{\text {fuel }}$ is the Prandtl-Schmidt number; typically $\sigma_{\text {fuel }}=0.7$; and $R_{\text {fuel }}$ is the fuel reaction rate inside the control volume.

In this work, the $k-\varepsilon$ model is used to describe turbulence properties during the explosion process. The conservation equations for the kinetic energy of turbulence $(k)$ and its rate of dissipation $(\varepsilon)$ are expressed as follows [20, 21].

Turbulent kinetic energy conservation equation is

$$
\begin{aligned}
& \frac{\partial}{\partial t}\left(\beta_{v} \rho k\right)+\frac{\partial}{\partial x_{j}}\left(\beta_{j} \rho u_{j} k\right) \\
& =\frac{\partial}{\partial x_{j}}\left(\beta_{j} \frac{\mu_{\mathrm{eff}}}{\sigma_{k}} \frac{\partial k}{\partial x_{j}}\right)+\beta_{v} P_{k}-\beta_{v} \rho \varepsilon .
\end{aligned}
$$

Dissipation rate of turbulent kinetic energy conservation equation is

$$
\begin{aligned}
& \frac{\partial}{\partial t}\left(\beta_{v} \rho \varepsilon\right)+\frac{\partial}{\partial x_{j}}\left(\beta_{j} \rho u_{j} \varepsilon\right) \\
& \quad=\frac{\partial}{\partial x_{j}}\left(\beta_{j} \frac{u_{\mathrm{eff}}}{\sigma_{\varepsilon}} \frac{\partial \varepsilon}{\partial x_{j}}\right)+\beta_{v} P_{\varepsilon}-C_{2} \beta_{v} \rho \frac{\varepsilon^{2}}{k},
\end{aligned}
$$

where $P_{k}$ is the turbulent kinetic energy; $P_{\varepsilon}$ is the production of dissipation; $\sigma_{k}$ and $\sigma_{\varepsilon}$ are the Prandtl-Schmidt numbers; typically $\sigma_{k}=1.0$ and $\sigma_{\varepsilon}=1.3 ; C_{2}$ is a constant in (7); typically $C_{2}=1.92$.

The stress tensor $\sigma_{i j}$ in the above equations is given by the following:

$$
\sigma_{i j}=\mu_{\mathrm{eff}}\left(\frac{\partial u_{i}}{\partial x_{j}}+\frac{\partial u_{j}}{\partial x_{i}}\right)-\frac{2}{3} \delta_{i j}\left(\rho k+\mu_{\mathrm{eff}} \frac{\partial u_{k}}{\partial x_{k}}\right),
$$

where $\delta_{i j}$ is Kronecker delta function. $\delta_{i j}=1$ if $i=j$, and $\delta_{i j}$ $=0$ if $i \neq j$.

The effective viscosity $\mu_{\text {eff }}$ is defined as follows:

$$
\mu_{\mathrm{eff}}=\mu+\rho C_{\mu} \frac{k^{2}}{\varepsilon}
$$

where $C_{\mu}$ is a constant; typically $C_{\mu}=1.92$. The second term of the right hand is known as the turbulent viscosity or eddy viscosity.

The turbulent kinetic energy $P_{k}$ is expressed as follows:

$$
P_{k}=G_{s}+G_{w}+G_{b}+G_{o}
$$

where $G_{s}$ is the flow shear stresses; $G_{w}$ is the wall shear stresses; $G_{b}$ is the buoyancy; and $G_{o}$ is the subgrid objects.

The production rate of turbulent kinetic energy $G_{s}$ due to shear stresses appears from the derivation of transport equation:

$$
G_{s}=\sigma_{i j} \frac{\partial u_{i}}{\partial x_{j}}
$$

The production $G_{b}$ due to buoyant forces is modelled by a single gradient model:

$$
G_{b}=-\frac{1}{\rho} \frac{\mu_{\mathrm{eff}}}{\sigma_{b}} g_{i} \frac{\partial \rho}{\partial x_{i}},
$$

where $\sigma_{b}$ is the Prandtl-Schmidt number, typically $\sigma_{b}=0.9$.

The turbulence generation $G_{o}$ due to subgrid obstructions is modelled by the following:

$$
G_{o}=C_{o} \beta_{v} \rho|\vec{u}| u_{i}^{2} f_{i}
$$

where $C_{o}$ is a model constant and $f_{i}$ is a parameter depending on subgrid objects.

The production of dissipation $P_{\varepsilon}$ is modelled as follows:

$$
P_{\varepsilon}=C_{1} \frac{\varepsilon}{k} P_{k}\left(1+C_{3} R_{f}\right)
$$

where $C_{1}$ and $C_{3}$ are constants, typically $C_{1}=1.44$ and $C_{3}=$ 0.8 .

The model for the buoyancy term $R_{f}$ in (14) is given by the following:

$$
R_{f}=-\frac{G_{b}}{P_{k}} \frac{|\vec{u} \times \vec{g}|}{|\vec{u}| \times|\vec{g}|}
$$

In FLACS, the buoyancy terms $G_{b}$ and $R_{f}$ are 0 when products are present.

2.2. Combustion Model. The combustion model consists of the flame model and the burning velocity model in FLACS. $\beta$ flame model is adopted to ensure flame propagation with a specified burning velocity in an explosion process, whose flame thickness is typically about $3-5$ grid cells.

During the very early phase of gas explosion, the flame is smooth and governed by molecular diffusion, and then the burning velocity is laminar. A short period of time after ignition, the flame becomes quasilaminar when instabilities lead to wrinkling of the flame. After a transition period, the flame reaches the turbulence regime. In FLACS, three different burning velocity models are used to simulate the above three burning phases, respectively, including the laminar flame model, the quasilaminar flame model, and the turbulent flame model. The laminar burning velocity depends on the type of gas, gas-air mixture, and pressure, which can be written as follows $[21,22]$ :

$$
S_{L}=S_{L 0}\left(\frac{p}{p_{0}}\right)^{r_{p}}
$$




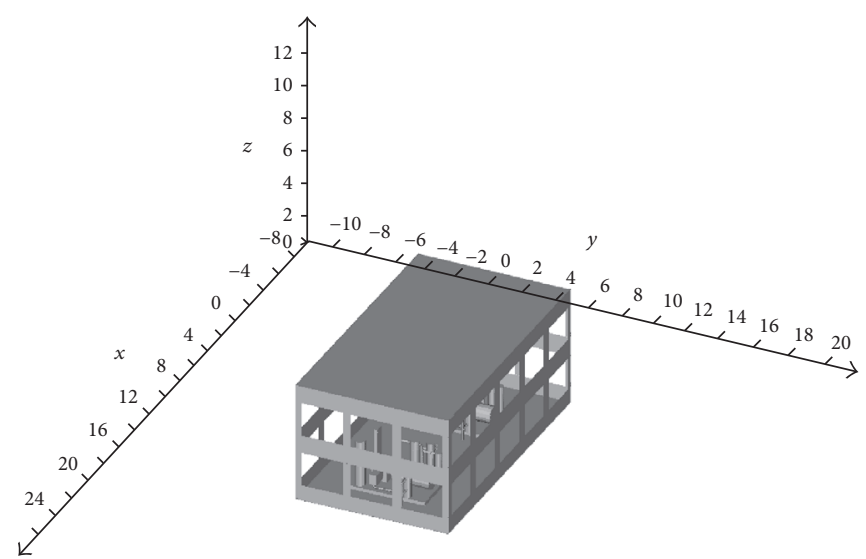

(a)

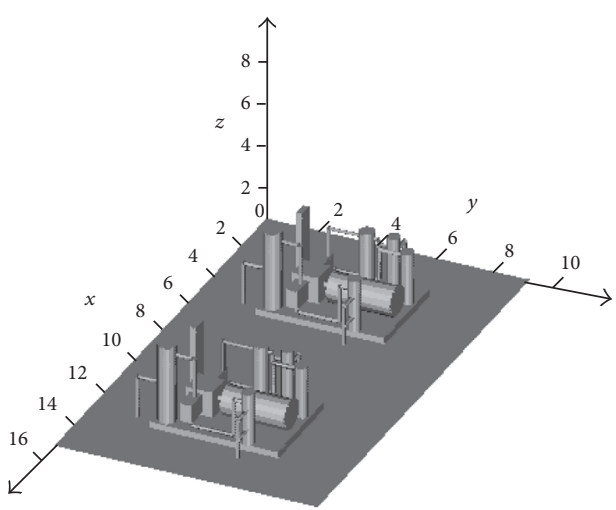

(b)

FIGURE 1: Geometry model: (a) computational domain; (b) geometries and placement of compressors.

where $S_{L}$ is the laminar burning velocity; $S_{L 0}$ is the burning velocity under a specific reference pressure; $p_{0}$ is the reference pressure; and $r_{p}$ is a gas-dependent parameter.

In the quasilaminar regime, the burning velocity is given by the following:

$$
S_{\mathrm{QL}}=S_{L}+8 S_{L}^{0.284} u^{10.912} l^{0.196},
$$

where $S_{\mathrm{QL}}$ is the quasilaminar burning velocity; $u^{\prime}$ is the rootmean-square of the turbulent velocity fluctuations; and $l$ is the turbulence length scale.

In the turbulent regime, the burning velocity is expressed as follows:

$$
S_{T}=15 S_{L}^{0.784} u^{10.412} l^{0.196},
$$

where $S_{T}$ is the turbulent burning velocity.

FLACS selects burning velocity as follows:

$$
S_{u}=\max \left(S_{T}, \min \left(S_{\mathrm{QL}}, S_{T}\right)\right),
$$

where $S_{u}$ is the chosen burning velocity.

2.3. Geometry and Computational Domain. The FLACS code solves differential forms of the conservation equations for mass, momentum, enthalpy, and chemical species on a threedimensional Cartesian grid using the finite volume method. In this work, FLACS is used to establish the geometry model of a compressor compartment according to the distributed porosity concept [22,23].

A typical gas compressor compartment operated by Dujiangyan Gas Co., Sichuan, China, is selected to study the explosion venting process in this study. The compartment has the dimensions of $15.6 \mathrm{~m}$ long, $9 \mathrm{~m}$ wide, and $7 \mathrm{~m}$ high, as shown in Figure 1(a). The total volume of the compressor compartment is $982.8 \mathrm{~m}^{3}$. Unless otherwise noted, two reciprocating compressors are configured inside the compartment during the subsequent simulations, as shown in Figure 1(b). The volume occupied by each compressor is approximately $7.866 \mathrm{~m}^{3} .32$ vents are evenly and symmetrically distributed within two layers along the external wall of the compressor compartment. Each vent has the dimensions of $2.5 \mathrm{~m}$ long and $2 \mathrm{~m}$ wide. The lower edge of lower vents is located at $0.9 \mathrm{~m}$ above the ground, while the lower edge of upper vents is located at $4 \mathrm{~m}$ above the ground.

2.4. Grid Independence. It is necessary to investigate the effect of grid size on the overpressure peak and the maximum rate of pressure rise to balance the computational accuracy and cost. The entire computational domain has the dimensions of $36 \mathrm{~m}$ long, $32 \mathrm{~m}$ wide, and $12 \mathrm{~m}$ high, as shown in Figure 1(a). To make the compressor compartment and vent panels fully resolved on the grid, three set of grids with a uniform cell size $(0.50 \mathrm{~m}, 0.30 \mathrm{~m}$, and $0.21 \mathrm{~m})$ are chosen to validate the accuracy of numerical solutions.

The numerical results of three set of grids are presented in Table 1. It can be found that the overpressure peak and the maximum rate of pressure rise inside the entire computational domain both depending on the grid resolution. The relative discrepancies of the overpressure peaks and the maximum rate of pressure rise between number 1 and number 2 are $13.09 \%$ and $18.02 \%$, respectively, whereas those between number 2 and number 3 further drop down to $6.41 \%$ and $3.17 \%$, respectively. These indicate that both grids (number 2 and number 3 ) are more suitable for numerical simulations. So as to save time and improve the computational efficiency, the medium grid (number 2) is used to perform all simulations in the following sections.

2.5. Initial and Boundary Conditions. The flammable gas cloud size mainly depends on the kinds of leakage sources, space dimensions, and ventilation conditions. In general, the maximum explosion overpressure would be generated when the volume ratio of gas fuel to air is close to the stoichiometric ratio $[4,5]$. In other words, the entire compartment filled with a gas cloud close to the stoichiometric ratio can be taken as the worst-case scenario. Thus, the initial condition prior to ignition is assumed that the entire compressor compartment is completely filled with a stoichiometric gas cloud. The compositions of natural gas released are listed in Table 2. 
TABLE 1: Results of grid independence.

\begin{tabular}{lccccc}
\hline $\begin{array}{l}\text { Grid } \\
\text { number }\end{array}$ & $\begin{array}{c}\text { Cell size } \\
(\mathrm{m})\end{array}$ & Grid cells & $\begin{array}{c}\text { Overpressure peak } \\
(\text { barg })\end{array}$ & $\begin{array}{c}\text { Max. rate of pressure rise } \\
(\text { barg/s) }\end{array}$ & $\begin{array}{c}\text { Computing time } \\
(\mathrm{h})\end{array}$ \\
\hline Number 1 & 0.50 & 110592 & 0.1016 & 10.51 & 1 \\
Number 2 & 0.30 & 513600 & 0.1169 & 12.82 & 5 \\
Number 3 & 0.21 & 1481544 & 0.1249 & 13.24 & 15 \\
\hline
\end{tabular}

TABLE 2: Compositions of natural gas released.

\begin{tabular}{lcccccrrr}
\hline Component & $\mathrm{CH}_{4}$ & $\mathrm{C}_{2} \mathrm{H}_{6}$ & $\mathrm{C}_{3} \mathrm{H}_{8}$ & $\mathrm{i}-\mathrm{C}_{4} \mathrm{H}_{10}$ & $\mathrm{n}-\mathrm{C}_{4} \mathrm{H}_{10}$ & $\mathrm{i}-\mathrm{C}_{5} \mathrm{H}_{12}$ & $\mathrm{CO}_{2}$ & $\mathrm{~N}_{2}$ \\
\hline Mole fraction (\%) & 92.5 & 3.96 & 0.335 & 0.116 & 0.0863 & 0.221 & 1.89 & 0.846 \\
\hline
\end{tabular}

TABLE 3: Comparisons of overpressure peak from numerical simulations and experiments.

\begin{tabular}{lccccc}
\hline $\begin{array}{l}\text { Vent area } \\
\left(\mathrm{m}^{2}\right)\end{array}$ & Number of obstacles & Ignition location & $\begin{array}{c}\text { Experiment } \\
(\text { barg })\end{array}$ & $\begin{array}{c}\text { Simulation } \\
(\text { barg })\end{array}$ & $\begin{array}{c}\text { Relative error } \\
(\%)\end{array}$ \\
\hline 2.7 & 0 & Back & 0.134 & 0.127 & 5.22 \\
2.7 & 8 & Center & 0.102 & 0.108 & 5.56 \\
5.4 & 0 & Back & 0.056 & 0.054 & 3.57 \\
5.4 & 8 & Center & 0.186 & 0.174 & 6.45 \\
\hline
\end{tabular}

All boundaries of the whole computational domain are set as the PLANE_WAVE boundary, with the exception to the solid ground which is set as the EULER boundary. An initial relative turbulence intensity of 0.1 and an initial turbulence length scale of $0.01 \mathrm{~m}$ are considered throughout the whole analysis. The ambient pressure is used as the reference pressure outside the boundaries [22]. The computational domain is initially defined with the standard atmospheric pressure and a temperature of $20^{\circ} \mathrm{C}$. In addition, the noslip boundary conditions are applied to the walls which are completely blocked, and the gradient of normal pressure, temperature, and density are all set as 0 . All venting panels are defined as the outlet boundaries. The porosity of the vents is set to 0 before explosion overpressure is less than the given vent activation pressure, while it would be switched to 0.7 when the vents are broken.

\section{Model Validation}

3.1. Propane-Air Explosion. In order to validate the present numerical model, the comparisons of the experimental and numerical results for the stoichiometric propane-air explosions were performed in a $63.7 \mathrm{~m}^{3}$ explosion test chamber [4]. The chamber has the dimensions of $4.6 \mathrm{~m}$ long, $4.6 \mathrm{~m}$ wide, and $3 \mathrm{~m}$ high and has a square vent of $5.4 \mathrm{~m}^{2}$ or $2.7 \mathrm{~m}^{2}$ located on the front wall. Two ignition locations, that is, the back ignition $(0.25 \mathrm{~m}$ from the center of the wall opposite the vent) and the center ignition (center of the chamber), are used, respectively. Four pressure transducers are mounted on the chamber walls to record the pressure-time histories [4].

The present numerical results are compared with the experimental results recorded by the pressure transducer P1 [4], as shown in Table 3. The relative errors of overpressure peak are all smaller than $7 \%$ between experimental and simulation results. In addition, Figure 2 illustrates that the trend of numerical simulations is approximately similar to

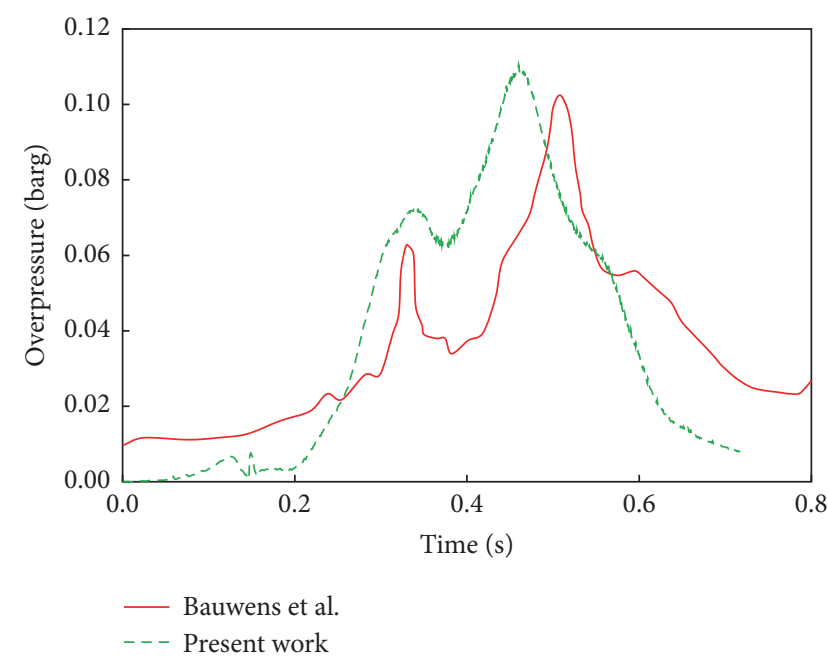

FIGURE 2: Overpressure versus time profiles obtained from the experiment and the numerical simulation (eight obstacles and a $2.7 \mathrm{~m}^{2}$ vent for center ignition).

that obtained from the experiments. It can be concluded that the numerical model is valid to reproduce the experimental results.

3.2. Methane-Air Explosion. Two sets of experiments in terms of stoichiometric methane-air explosions were used to further validate the accuracy of the present model. The experiments were carried out by Hjertager et al. in a $27 \mathrm{~m}^{3}$ cubical vessel, which has the dimensions of $3 \mathrm{~m}$ long, $3 \mathrm{~m}$ wide, and $3 \mathrm{~m}$ high [24]. Ten pressure transducers are mounted at various positions along the two diagonals to record the explosion overpressure. The ignition source is located in the vessel corner. Two obstacle arrangements inside the vessel, that is, the obstacles' diameter $D=820 \mathrm{~mm}$ with the volume 
TABLE 4: Relevant parameters of accident scenarios.

\begin{tabular}{lc}
\hline Parameters & Numerical values \\
\hline Vent area ratio $\left(K_{v}\right)$ & $0.1,0.2,0.5,0.8,1.0,1.1,1.2$ and 1.6 \\
Activation pressure $\left(P_{\text {stat }}\right)$ & $0.05,0.1,0.15,0.2,0.25$ and $0.3 \mathrm{barg}$ \\
Mass per unit area of vent panels & $5,10,12.5,20,40$ and $60 \mathrm{~kg} \cdot \mathrm{m}^{-2}$ \\
Volume blockage ration $(V B R)$ & $0,0.008,0.016,0.024$ and 0.032 \\
\hline
\end{tabular}

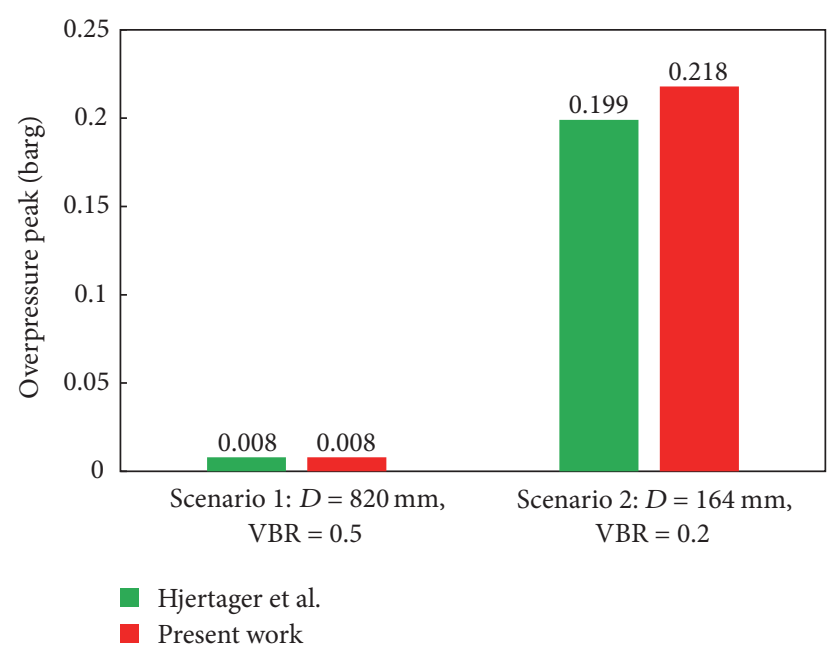

FIgURE 3: Comparison of the results obtained by experiment and numerical simulations.

blockage ratio $(\mathrm{VBR})=0.5$ and $D=164 \mathrm{~mm}$ with $\mathrm{VBR}=0.2$, are taken into account in this paper.

The peak overpressures recorded by those pressure transducers [24] and the numerical results obtained from the present work were summarized in Figure 3. It can be found that the numerical results are both in good agreement with the experimental results for the explosion scenarios.

\section{Numerical Results and Discussion}

4.1. Simulation Conditions. Numerical simulations are performed for different explosion venting scenarios by varying one parameter per time to analyze the variation of pressure peaks in a compressor compartment, while maintaining all other parameters unchanged. A summary of the initial data for these simulations is shown in Table 4, including vent area ratio $\left(K_{v}\right)$, vent activation pressure $\left(P_{\text {stat }}\right)$, mass per unit area of vent panels, and volume blockage ratio (VBR) of obstacles. The vent area ratio $\left(K_{v}\right)$ is introduced to quantitatively investigate the effect of vent area on the pressure peaks. In this paper, the vent area ratio is defined as $K_{v}=A_{v} / V^{2 / 3}$ [25], where $A_{v}$ is the vent area and $V$ is the volume of a compressor compartment. The VBR is defined as the volume fraction occupied by compressors inside the compartment, characterizing the degree of obstruction [24].

4.2. Explosion Venting Characteristics. In this section, the compressor compartment shown in Figure 1 is studied to investigate the explosion venting characteristics. Other important parameters for the explosion venting scenario are

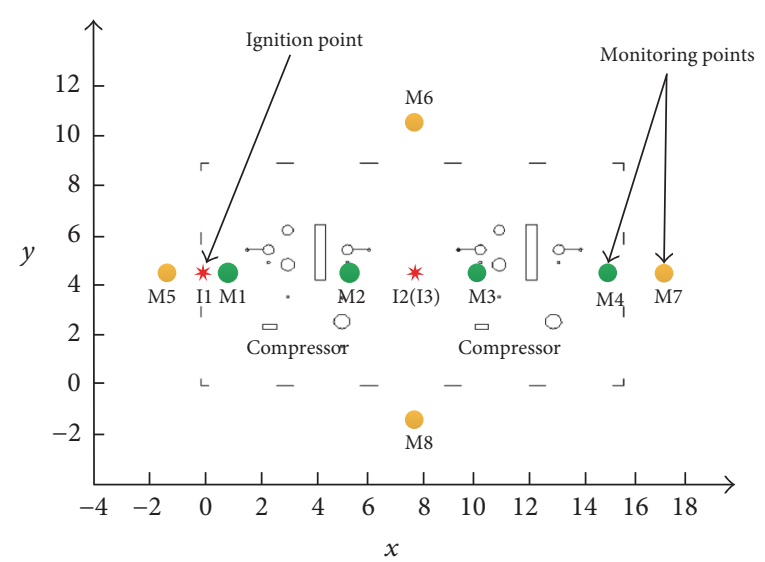

FIGURE 4: Distribution of ignition points and monitoring points.

as follows: the vent area ratio of 1.6 , vent activation pressure of $0.1 \mathrm{barg}$, the mass per unit area of vent panels of $5 \mathrm{~kg} \cdot \mathrm{m}^{-2}$, and the volume blockage ratio of obstacles of 0.016 .

4.2.1. Ignition Location. The gas explosion venting characteristics are strongly dependent on ignition location $[4,5]$. Thus, the effect of ignition location should be discussed first. Three ignition locations, namely, I1 $(0.2,4.5,0.2)$, I2 (7.8, 4.5, 0.2), and I3 $(7.8,4.5,3.5)$, are compared in this paper, as illustrated in Figure 4.

The overpressure peaks obtained for the three different ignition points in the entire compartment are shown in Figure 5. The comparison shows that ignition location I1 generates a significantly higher overpressure peak compared to I2. For ignition location I1, the flame would travel from one end of the compartment to the other end along $x$ axis, resulting in the farthest flame propagation distance. During this process, the flame front surface interacts with the compressor two times. Thus the higher turbulence intensity would be generated, which contributes to speeding up the flame combustion rate and creating a higher overpressure peak. In addition, the overpressure peak caused by ignition location $\mathrm{I} 2$ is higher than that caused by ignition location I3. The reason of this phenomenon lies in the fact that the presence of compressors on the ground increases the flame surface area and turbulence intensity.

4.2.2. Time-Varying Characteristics of Explosion Pressure. The time-varying characteristic of explosion pressure involves gas combustion and expansion, unburned and burned gas venting, external deflagration, flame front surface development, flame instabilities, and flame acoustic interactions [26]. Thus, the evolution of pressure along the pressure-time history is 


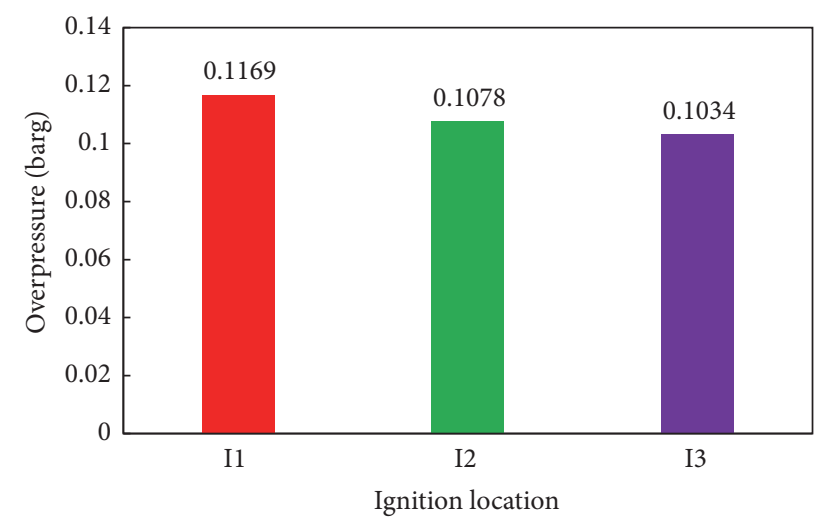

FIGURE 5: Overpressure peaks for three different ignition points.

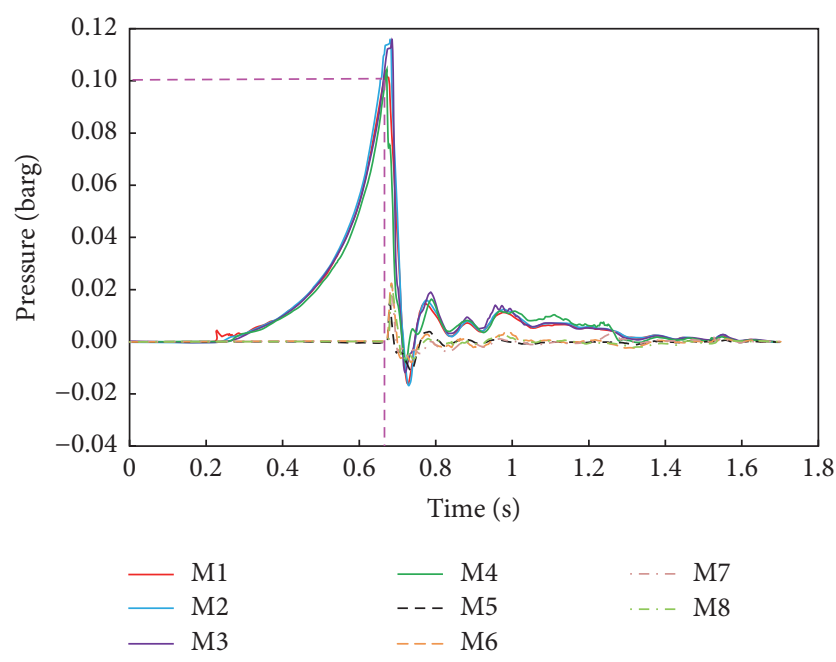

FIGURE 6: Pressure-time profiles obtained at different monitoring points for ignition location I1.

the result of the interactions among these complex physical phenomena. To analyze the variations of explosion pressure, eight typical monitoring points are arranged on the plane $z$ $=1.4 \mathrm{~m}$, including $\mathrm{M} 1(0.4,4.5,1.4), \mathrm{M} 2(5.2,4.5,1.4)$, M3 (10.4, 4.5, 1.4), and M4 $(15.2,4.5,1.4)$ inside the compartment as well as M5 $(-1.5,4.5,1.4)$, M6 $(7.8,10.5,1.4)$, M7 (17.1, $4.5,1.4)$, and M8 $(7.8,-1.5,1.4)$ outside the compartment, as shown in Figure 4. Figure 6 shows the pressure-time curves obtained at different monitoring points for the ignition location I1 (illustrated in Figure 4). Figures 7 and 8 present the development of fuel cloud and flame along with time on the plane $z=1.4 \mathrm{~m}$, respectively.

As can be seen from Figure 6, the first pressure peaks are observed within $0.67-0.68 \mathrm{~s}$ for all the eight monitoring points. Furthermore, the explosion pressure exceeds the given vent activation pressure at approximately $0.67 \mathrm{~s}$. Consequently, almost all the vents are activated at the same time, causing emissions of unburned gas prior to that of burned gas, as shown in Figure 7.

When the burned gas reaches the vent (i.e., $0.72 \mathrm{~s}$ shown in Figure 7), the volumetric venting rate of gas exiting the compartment is substantially increased due to the decrease in density of the vented gas. When the venting exceeds the volume expansion resulting from combustion, the internal pressure is decreased in the compartment. However, the burned gas is overvented due to the inertia of outflow. Consequently, a substantial negative pressure would be generated, as shown in Figure 6. In addition, this process might trigger a Helmholtz oscillation, causing the internal pressure to oscillate around the equilibrium pressure [27].

When the flame interacts with compressors, the front surface would wrinkle and produce a larger flame surface area, as illustrated in Figures 7 and 8. However, the pressure peaks generated by interactions between the flame surface, flame acoustics, and the structure of the compartment itself are not significant, which may be due to the large vent area in the model.

\subsection{Analysis of Impact Factors}

4.3.1. Effect of Vent Area Ratio. The relevant parameters listed in Table 4 are used to analyze the effect of vent area ratio $\left(K_{v}\right)$ on the pressure peaks (namely, overpressure and negative pressure) under different vent activation pressure $\left(P_{\text {stat }}\right)$. Figure 9 shows the typical pressure variations of vented explosion for the vent activation pressure of $0.1 \mathrm{barg}, 0.2 \mathrm{barg}$, and $0.3 \mathrm{barg}$, with varying the vent area ratio from 0.1 to 1.6. In all the cases, the mass per unit area of vent panels is set to $5 \mathrm{~kg} \cdot \mathrm{m}^{-2}$ and the volume blockage ratio of obstacles is 0.016 .

As can be seen, given a fixed $P_{\text {stat }}$, the overpressure and negative pressure peaks both decrease with the increase of vent area ratio. The reason of this phenomenon lies in the fact that the larger vent area results in more combustible gas expelled from a compressor compartment at the same time. In addition, the pressure peaks decrease rapidly at $K_{v}<0.5$, while they are almost independent of vent area ratio at $K_{v}>$ 0.5 . Therefore, the vent area ratio $K_{v}=0.5$ is recommended to use as the minimum vent area ratio in the venting design of compressor compartments.

Figure 10 illustrates the comparisons of simulation results with the values calculated according to EN 14494 and NFPA 68 at $P_{\text {stat }}=0.1$ barg under different vent area ratio. As can be seen, the general trend of simulation results is similar to those obtained by EN 14494 and NFPA 68 . When $K_{v}$ is less than 0.5 , the overpressures calculated from NFPA 68 or EN 14494 are both greater than those obtained by numerical simulations, and the maximum discrepancy might exceed 1.0 barg. However, the discrepancies of peak overpressure decrease with the increase of $K_{v}$ when $K_{v}$ is larger than 0.5 .

4.3.2. Effect of Vent Activation Pressure. The relevant parameters listed in Table 4 are used to analyze the effect of activation pressure $\left(P_{\text {stat }}\right)$ on the pressure peaks (i.e., overpressure and negative pressure) under different vent area ratio $\left(K_{v}\right)$. The pressure peaks recorded for vent area ratio of $0.5,1.1$, and 1.6 with vent activation pressures ranging from 0.05 barg to 0.3 barg are all presented in Figure 11. In all the cases, the mass per unit area of vent panels is set to $5 \mathrm{~kg} \cdot \mathrm{m}^{-2}$ and the volume blockage ratio of obstacles is 0.016 .

There is an approximate linearly increasing relationship between the pressure peaks and the activation pressure for a 


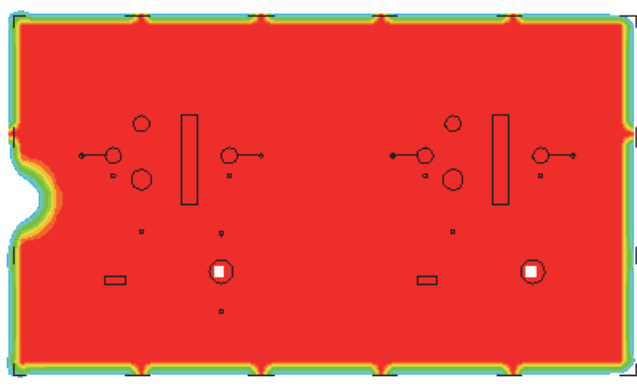

$0.30 \mathrm{~s}$

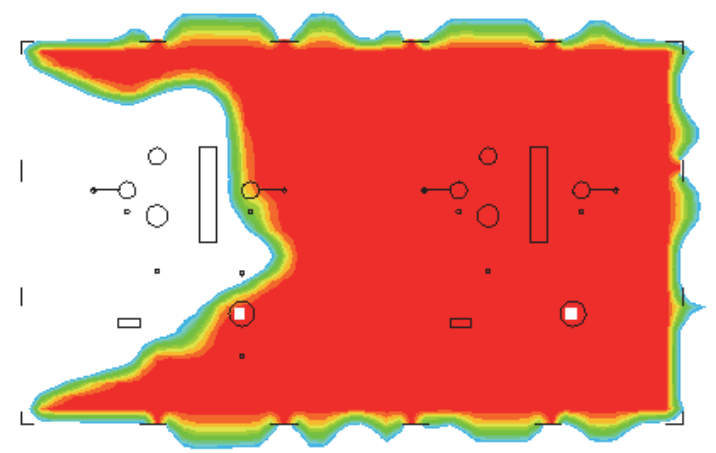

$0.67 \mathrm{~s}$

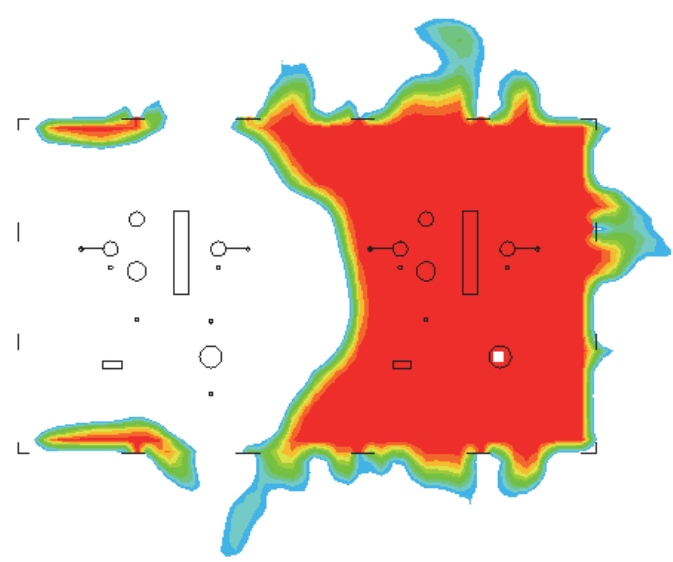

$0.78 \mathrm{~s}$

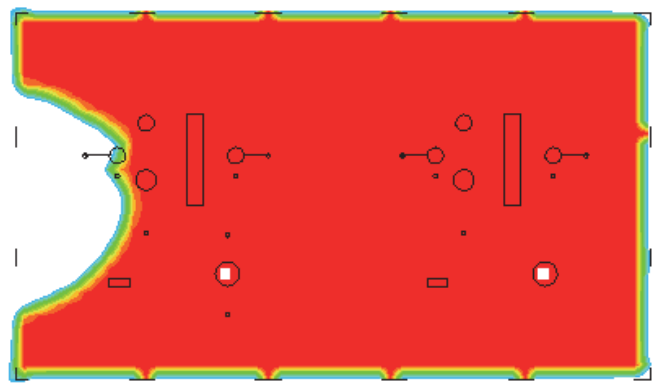

$0.50 \mathrm{~s}$

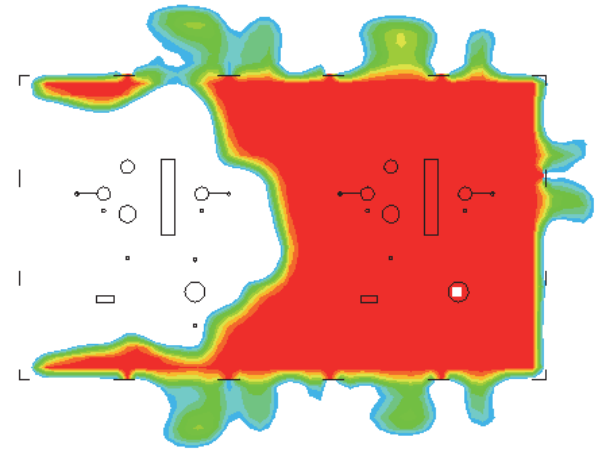

$0.72 \mathrm{~s}$

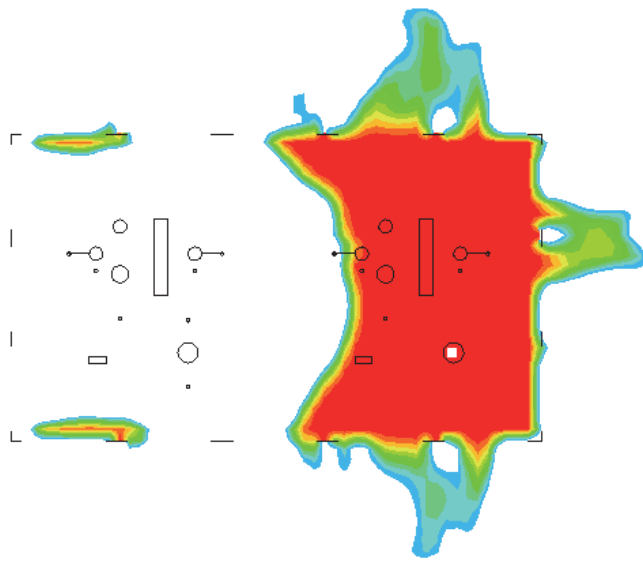

$0.85 \mathrm{~s}$

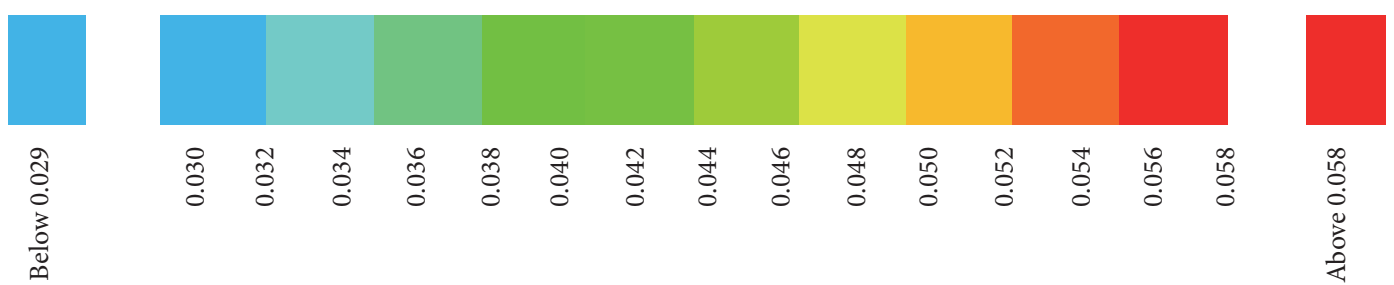

Figure 7: Simulated fuel cloud development $(z=1.4 \mathrm{~m})$. The contours represent the mass fraction of fuel. Six time steps are plotted: $0.3 \mathrm{~s}$, $0.5 \mathrm{~s}, 0.67 \mathrm{~s}, 0.72 \mathrm{~s}, 0.78 \mathrm{~s}$, and $0.85 \mathrm{~s}$.

fixed $K_{v}$, as shown in Figure 11. The increase of vent activation pressure will induce a delay in the opening time of vent, which enhances the unburned gas compressibility and turbulent intensity and thus causes an increment in pressures.
Figure 12 illustrates the comparisons of simulation results with the values calculated according to EN 14494 and NFPA 68 at $K_{v}=0.2$ under different vent activation pressure $\left(P_{\text {stat }}\right)$. As can be seen, the general trend of simulation results is 

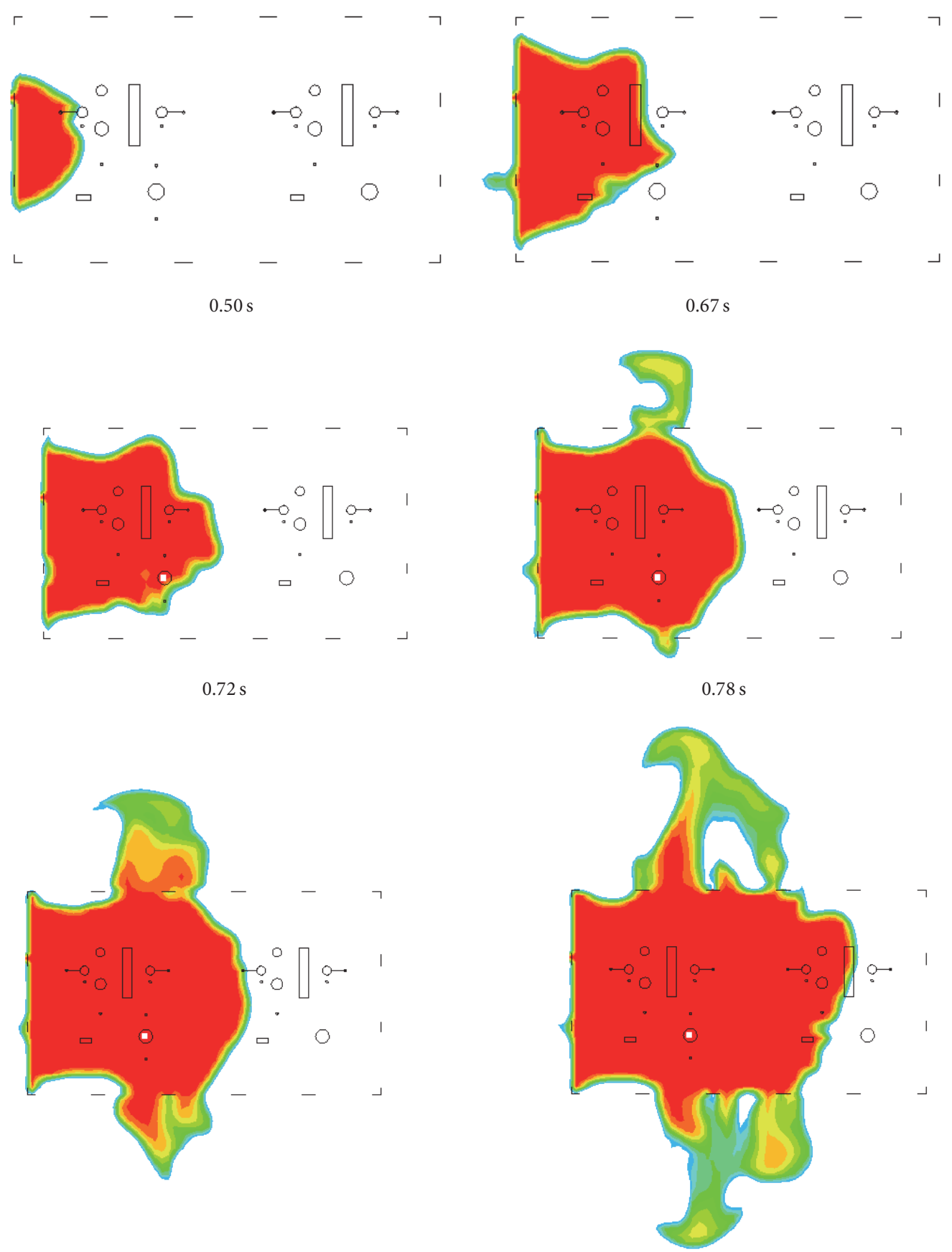

$0.85 \mathrm{~s}$

$1.0 \mathrm{~s}$
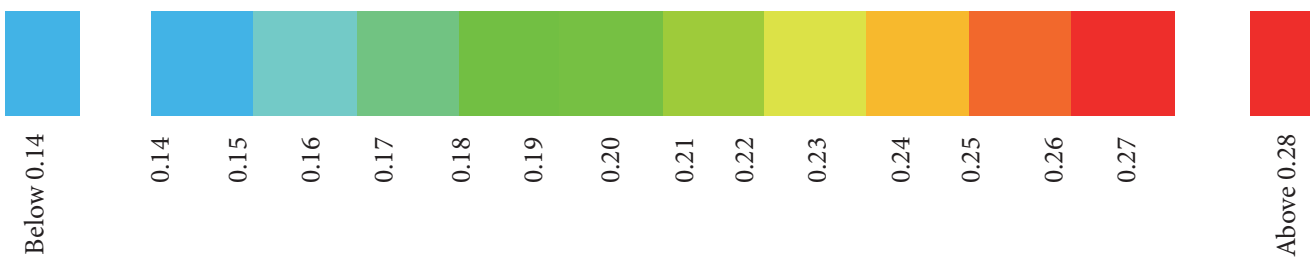

Figure 8: Simulated flame development $(z=1.4 \mathrm{~m})$. The contours represent the mass fraction of combustion products. Six time steps are plotted: $0.5 \mathrm{~s}, 0.67 \mathrm{~s}, 0.72 \mathrm{~s}, 0.78 \mathrm{~s}, 0.85 \mathrm{~s}$, and $1.0 \mathrm{~s}$. 


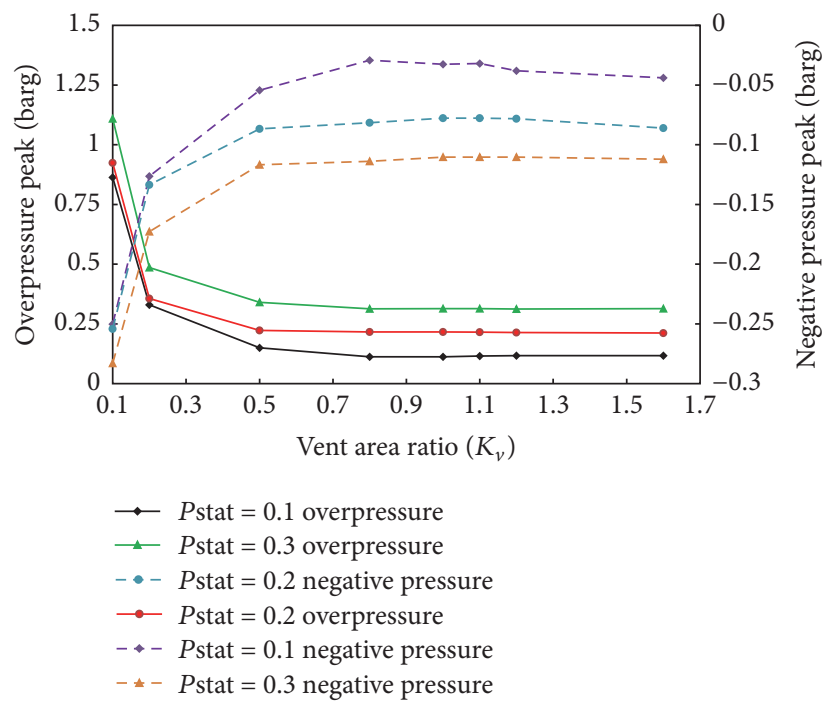

FIGURE 9: Variations of pressure peaks with different vent area ratio $\left(K_{v}\right)$.

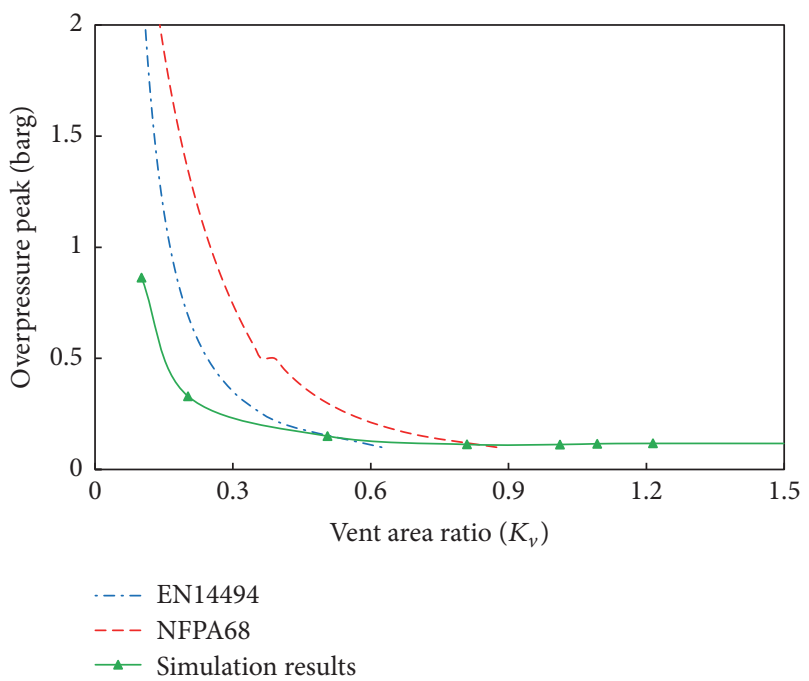

FIGURE 10: Comparison of results obtained by simulations, EN 14494 and NFPA $68\left(P_{\text {stat }}=0.1 \mathrm{barg}\right)$.

similar to those obtained by EN 14494 and NFPA 68. The values calculated according to NFPA 68 are approximately 1.0 barg higher than those obtained by numerical simulations for a fixed $P_{\text {stat }}$. When $P_{\text {stat }}$ is more than 0.1 barg, the discrepancy of overpressure peak between simulation results and the values predicted by EN 14494 increases with the vent activation pressure.

4.3.3. Effect of Mass per Unit Area of Vent Panels. The relevant parameters listed in Table 4 are used to analyze the effect of the mass per unit area of vent panels on the pressure peaks (i.e., overpressure and negative pressure) under different vent area ratios $\left(K_{v}\right)$. The pressure peaks recorded for vent area ratio of $0.2,0.5$, and 0.8 are all presented in Figure 13, with varying mass per unit area of vent panels from $5 \mathrm{~kg} \cdot \mathrm{m}^{-2}$ to

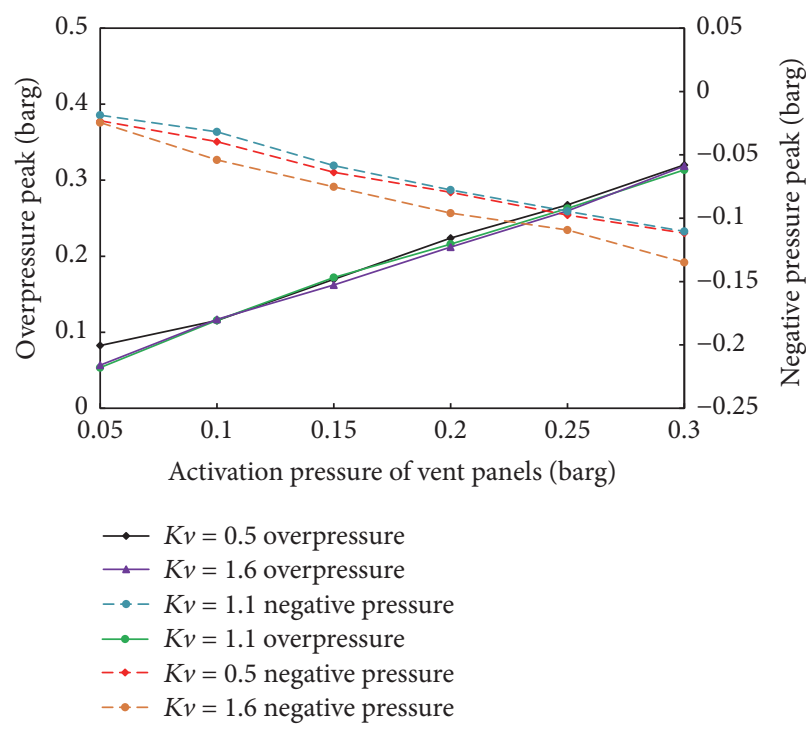

FIGURE 11: Variations of pressure peaks with different vent activation pressure $\left(P_{\text {stat }}\right)$.

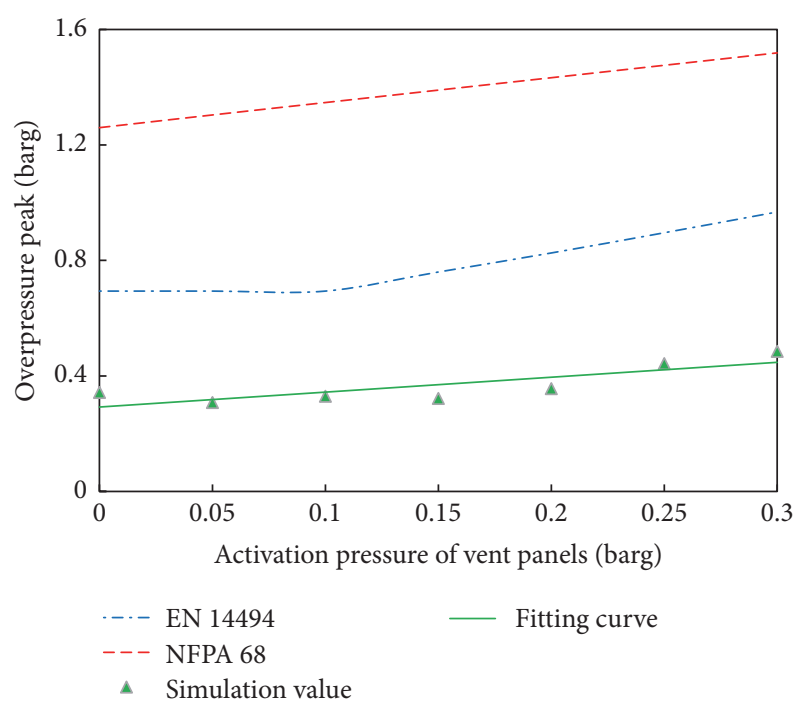

FIGURE 12: Comparison of results obtained by simulations, EN 14494 and NFPA $68\left(K_{v}=0.2\right)$.

$60 \mathrm{~kg} \cdot \mathrm{m}^{-2}$. In all the cases, the activation pressure $\left(P_{\text {stat }}\right)$ of vent panels is set to 0.1 barg and the volume blockage ratio of obstacles is 0.016 .

As can be seen, the pressure peaks increases with the mass per unit area of vent panels for a fixed $K_{v}$. The reason of this phenomenon lies in the fact that the greater the mass per unit area is, the more significant the inertia effect of vent panels is. The inertia effect will lead to a delay in the opening time of vent and damp the discharge of unburned gas and thus increase overpressures. Therefore, the low-density and low-intensity materials should be selected as the vent panels to minimize the inertia of vent panels in partially closed or fully closed compressor compartments, from the point of controlling explosion peaks. 
TABLE 5: Levels and factors.

\begin{tabular}{lcccc}
\hline Levels & Vent area ratio & $\begin{array}{c}\text { Vent activation pressure } \\
(\text { barg })\end{array}$ & $\begin{array}{c}\text { Impact Factors } \\
\text { Mass per unit area of vent panels } \\
\left(\mathrm{kg} \cdot \mathrm{m}^{-2}\right)\end{array}$ & $\begin{array}{c}\text { Volume blockage ratio } \\
1\end{array}$ \\
\hline 0.1 & 0.05 & 10 & 0 \\
2 & 0.2 & 0.10 & 20 & 0.008 \\
3 & 0.5 & 0.15 & 40 & 0.016 \\
4 & 0.8 & 0.20 & 60 & 0.032 \\
5 & 1.2 & 0.25 & 0.032 \\
\hline
\end{tabular}

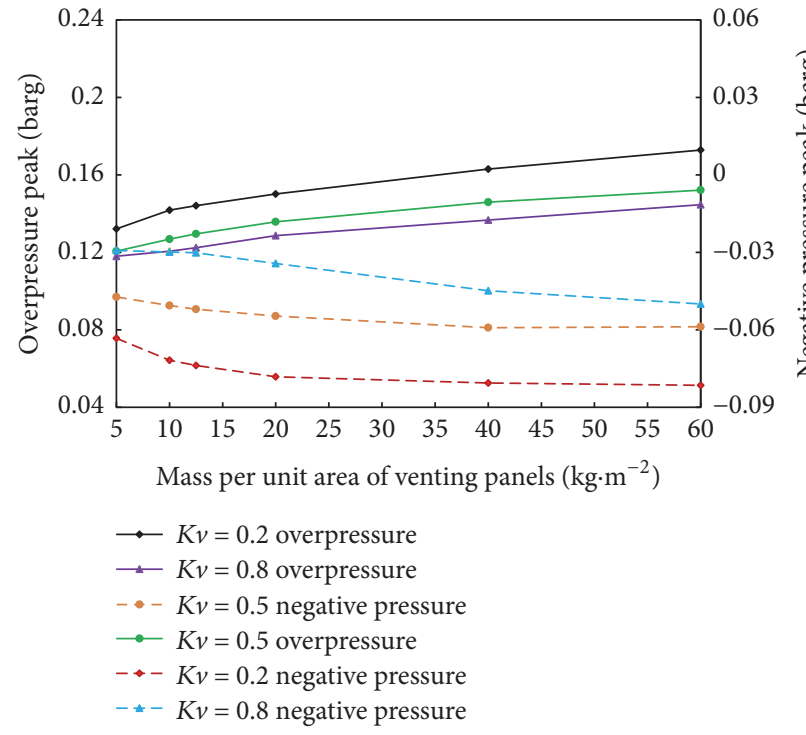

FIGURE 13: Variations of pressure peaks with different mass per unit area.

4.3.4. Effect of Volume Blockage Ratio of Obstacles. In this section, numerical simulations are performed by varying the numbers of compressors in the compartment. The relevant parameters listed in Table 4 are used to analyze the effect of volume blockage ratio on the pressure peaks (i.e., overpressure and negative pressure) under different vent area ratios $K_{v}$. The pressure peaks for $K_{v}$ of $0.2,0.5$, and 0.8 are all presented in Figure 14, with varying the volume blockage ratio of obstacles from 0 to 0.032 (i.e., the number of compressors ranging from 0 to 4 ). In all cases, the activation pressure $\left(P_{\text {stat }}\right)$ of vent panels is set to 0.1 barg and the mass per unit area of vent panel is set to $5 \mathrm{~kg} \cdot \mathrm{m}^{-2}$.

As illustrated in Figure 14, given a fixed $K_{v}$, the pressure peaks increase with the volume blockage ratio of obstacles. This is due to the fact that the larger the volume blockage ratio is, the greater the degree of obstruction will be in the compartment. Under these situations, the flow resistance during the venting process would be enhanced, and thus the turbulent intensity and overpressures are increased. Furthermore, the effect of volume blockage ratio on the pressure peaks is much more significant for a smaller vent area ratio.

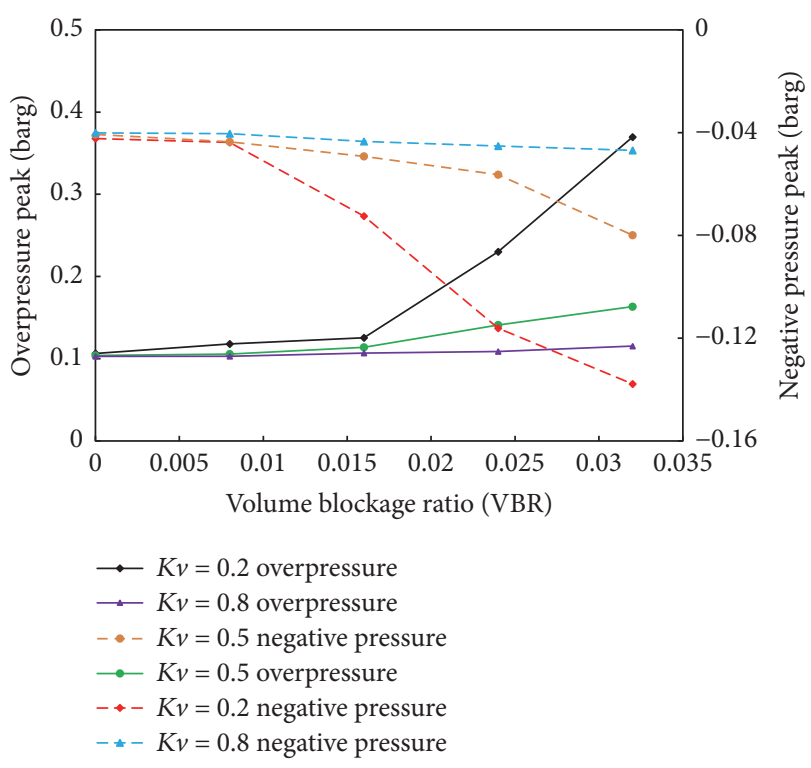

FIGURE 14: Variations of pressure peaks with different volume blockage ratios.

\subsection{Relative Importance of Various Impact Factors}

4.4.1. Orthogonal Experimental Design. The orthogonal experimental design is a mathematical method to address the tests of multiple factors and levels [28]. The key of this method is to make an orthogonal design table based on the reasonable and representative levels of the investigated factors. This method can select representative cases and evaluate relative importance of each factor. In this work, an orthogonal experimental table of 4 factors and 5 levels is designed, as listed in Table 5. 25 cases are simulated, as shown in Table 6. The overpressure peak is taken as the evaluation index to identify the relative importance of various impact factors.

4.4.2. Grey Relational Analysis. Grey relational analysis is an effective statistical method to identify uncertain relations between one main factor and all other factors in a given grey system [29]. It has been widely applied into impact factor analysis [30], scheme decision-making [31], and comprehensive assessments [32]. In this work, the improved grey relational analysis is adopted to analyze the orthogonal experimental results. The primary steps are as follows [33]. 
TABLE 6: Results of orthogonal experimental design.

\begin{tabular}{|c|c|c|c|c|c|}
\hline Case & Vent area ratio & $\begin{array}{l}\text { Vent activation pressure } \\
\text { (barg) }\end{array}$ & $\begin{array}{l}\text { Mass per unit area of vent panels } \\
\left(\mathrm{kg} \cdot \mathrm{m}^{-2}\right)\end{array}$ & $\begin{array}{l}\text { Volume blockage } \\
\text { ratio }\end{array}$ & $\begin{array}{l}\text { Overpressure peak } \\
\text { (barg) }\end{array}$ \\
\hline (1) & 0.1 & 0.05 & 5 & 0 & 0.1545 \\
\hline (2) & 0.1 & 0.10 & 10 & 0.008 & 0.2918 \\
\hline (3) & 0.1 & 0.15 & 20 & 0.016 & 0.3225 \\
\hline (4) & 0.1 & 0.20 & 40 & 0.024 & 0.8971 \\
\hline$(5)$ & 0.1 & 0.25 & 60 & 0.032 & 1.1497 \\
\hline (6) & 0.2 & 0.05 & 10 & 0.032 & 0.3593 \\
\hline (7) & 0.2 & 0.10 & 20 & 0 & 0.1129 \\
\hline (8) & 0.2 & 0.15 & 40 & 0.008 & 0.1729 \\
\hline (9) & 0.2 & 0.20 & 60 & 0.016 & 0.2598 \\
\hline$(10)$ & 0.2 & 0.25 & 5 & 0.024 & 0.3126 \\
\hline (11) & 0.5 & 0.05 & 40 & 0.016 & 0.0848 \\
\hline (12) & 0.5 & 0.10 & 60 & 0.024 & 0.1668 \\
\hline (13) & 0.5 & 0.15 & 5 & 0.032 & 0.2095 \\
\hline (14) & 0.5 & 0.20 & 10 & 0 & 0.2065 \\
\hline (15) & 0.5 & 0.25 & 20 & 0.008 & 0.2573 \\
\hline (16) & 0.8 & 0.05 & 60 & 0.008 & 0.0573 \\
\hline (17) & 0.8 & 0.10 & 5 & 0.016 & 0.1127 \\
\hline (18) & 0.8 & 0.15 & 10 & 0.024 & 0.1985 \\
\hline (19) & 0.8 & 0.20 & 20 & 0.032 & 0.2940 \\
\hline$(20)$ & 0.8 & 0.25 & 40 & 0 & 0.2570 \\
\hline (21) & 1.2 & 0.05 & 20 & 0.024 & 0.0722 \\
\hline (22) & 1.2 & 0.10 & 40 & 0.032 & 0.1695 \\
\hline (23) & 1.2 & 0.15 & 60 & 0 & 0.1629 \\
\hline (24) & 1.2 & 0.20 & 5 & 0.008 & 0.2037 \\
\hline (25) & 1.2 & 0.25 & 10 & 0.016 & 0.2705 \\
\hline
\end{tabular}

Step 1. Set the reference sequences as $X_{0}=\left\{x_{0}(t), t=1,2\right.$, $\ldots, n\}$, and the comparative sequences as $X_{i}=\left\{x_{i}(t), t=1\right.$, $2, \ldots, n\}, i=1,2, \ldots, m$ :

$$
\begin{aligned}
& y_{i}(t+1)=x_{i}(t+1)-x_{i}(t) \\
& y_{0}(t+1)=x_{0}(t+1)-x_{0}(t) \quad(t=1,2, \ldots, n-1)
\end{aligned}
$$

Step 2. Calculate the relative change rate $k$ :

$$
\begin{aligned}
& k_{i}(t+1)=\frac{y_{i}(t+1)}{\overline{x_{i}}}, \quad \overline{x_{i}}=\frac{\sum_{t=1}^{n} x_{i}(t)}{n} \\
& k_{0}(t+1)=\frac{y_{0}(t+1)}{\overline{x_{0}}}, \quad \overline{x_{0}}=\frac{\sum_{t=1}^{n} x_{0}(t)}{n} .
\end{aligned}
$$

Step 3. Calculate the grey relational coefficients $\zeta_{i}(t)$ :

$$
\zeta_{i}(t)=\frac{ \pm 1}{1+\left\|k_{i}(t)|-| k_{0}(t)\right\|}
$$

In (22), if both $y_{i}(t)$ and $y_{0}(t)$ are the same symbol or 0 , take the plus; otherwise, take the minus.
Step 4. Calculate the grey relational grade $\gamma_{i}$ between $X_{i}$ and $X_{0}$ :

$$
\gamma_{i}=\frac{\sum_{y=2}^{n} \zeta_{i}(t)}{(n-1)} .
$$

In (23), the grey relational grade $\gamma_{i}$ varies from -1 to 1 . $\left|\gamma_{i}\right|$ represents the magnitude of the relational grade among various impact factors.

Step 5 (Rank). The impact degrees of investigated factors are ranked based on the magnitude of the grey relational grade.

As shown in Table 6, the overpressure peak columns are set as the reference sequence, whereas the remaining 4 columns are set as comparative sequences. The results of the relational grade calculated according to the above steps are presented in Table 7.

As can be seen from Table 7, the grey relational grades of four parameters (i.e., vent area ratio, vent activation pressure, mass per unit area of panels, and volume blockage ratio of obstacles) are $0.2423,0.5420,0.2211$, and 0.5542 , respectively. It means that the effects of four factors on overpressure peaks are ranked as follows: volume blockage ratio > vent activation pressure $>$ vent area ratio $>$ mass per unit area of vent panels. 
TABLE 7: Results of relational grade.

\begin{tabular}{lcccc}
\hline Factors & Vent area ratio & Vent activation pressure & Mass per unit area of vent panels & Volume blockage ratio \\
\hline$i$ & 1 & 2 & 3 & 4 \\
$\gamma_{i}$ & 0.2423 & 0.5420 & 0.2211 & 0.5542 \\
\hline
\end{tabular}

Furthermore, the grey relational grades for volume block ratio and vent activation pressure are much greater than those for vent area ratio and mass per unit area of vent panels. Therefore, more attention should be paid to how to effectively reduce the degree of obstruction inside compartments and the activation pressure of vent panels during the venting safety design of gas compressor compartments.

\section{Conclusions}

In this paper, a series of vented explosions in a typical compressor compartment, operated by Dujiangyan Gas Co., Sichuan, China, are simulated using FLACS package to analyze the explosion venting characteristics. The effects of relevant parameters on the peak pressures are also numerically analyzed, including vent area ratio, vent activation pressure, mass per unit area of vent panels, and volume blockage ratio of obstacles. In addition, the orthogonal experiment design and improved grey relational analysis are implemented to evaluate the relative importance of these parameters.

Simulation results indicate that almost all the vents are activated at the same time, leading to emissions of unburned gas prior to that of burned gas. A Helmholtz oscillation might be triggered during the venting process, causing the internal pressure to oscillate around the equilibrium pressure. Furthermore, several conclusions are drawn from the analysis of impact factors: the pressure peaks decrease with the increase of vent area ratio, whereas they are independent of the vent area ratio when the vent area ratio exceeds 0.5 ; there is an approximately linearly increasing relationship between pressure peaks and vent activation pressure; the pressure peaks increase with the mass per unit area of vent panels; the pressure peaks increase with the volume blockage ratio of obstacles, especially for the situations with a smaller vent area ratio. Meanwhile, the general trends of simulation results are similar to those obtained by EN 14494 and NFPA 68 under different vent area ratio or vent activation pressure.

The grey relational grades of four parameters (i.e., vent area ratio, vent activation pressure, mass per unit area of panels, and volume blockage ratio of obstacles) are 0.2423 , $0.5420,0.2211$, and 0.5542 , respectively. This indicates that the effects of these parameters on overpressure peaks are ranked as follows: volume blockage ratio $>$ vent activation pressure > vent area ratio > mass per unit area of vent panels. Compared with the vent area ratio and the mass per unit area of vent panels, the degree of obstruction inside compartments and the activation pressure of vent panels play much more significant roles in controlling explosion overpressure peaks. Thus, more attention should be paid to these two parameters during the venting safety design of gas compressor compartments.

\section{Conflicts of Interest}

The authors declare that they have no conflicts of interest.

\section{Acknowledgments}

The authors gratefully acknowledge financial support from the National Natural Science Foundation of China (no. 51474184) and the Natural Science Foundation of the State Administration of Work Safety in China (no. 2012-387, Sichuan-0021-2016AQ).

\section{References}

[1] API 581, Risk Based Resource Document, American Petroleum Institute, Washington, Wash, USA, 2008.

[2] V. Ebadat, "Dust explosion hazard assessment," Journal of Loss Prevention in the Process Industries, vol. 23, no. 6, pp. 907-912, 2010.

[3] Q. Liu, Y. Zhang, F. Niu, and L. Li, "Study on the flame propagation and gas explosion in propane/air mixtures," Fuel, vol. 140, pp. 677-684, 2015.

[4] C. R. Bauwens, J. Chaffee, and S. Dorofeev, "Effect of ignition location, vent size, and obstacles on vented explosion overpressures in propane-air mixtures," Combustion Science and Technology, vol. 182, no. 11-12, pp. 1915-1932, 2010.

[5] G. Tomlin, D. M. Johnson, P. Cronin, H. N. Phylaktou, and G. E. Andrews, "The effect of vent size and congestion in large-scale vented natural gas/air explosions," Journal of Loss Prevention in the Process Industries, vol. 35, pp. 169-181, 2015.

[6] B. M. Fakandu, G. E. Andrews, and H. N. Phylaktou, "Vent burst pressure effects on vented gas explosion reduced pressure," Journal of Loss Prevention in the Process Industries, vol. 36, pp. 429-438, 2015.

[7] R. M. Kasmani, G. E. Andrews, and H. N. Phylaktou, "Experimental study on vented gas explosion in a cylindrical vessel with a vent duct," Process Safety and Environmental Protection, vol. 91, no. 4, pp. 245-252, 2013.

[8] Y. K. Pu, Fundamental characteristics of laminar and turbulent flames in cornstarch dust air mixtures [Ph.D thesis], Department of Mechanic Engineering, McGill University, Montreal, Quebec, Canada, 1988.

[9] S. Höchst and W. Leuckel, "On the effect of venting large vessels with mass inert panels," Journal of Loss Prevention in the Process Industries, vol. 11, no. 2, pp. 89-97, 1998.

[10] J. Sustek and B. Janovsky, "Comparison of empirical and semiempirical equations for vented gas explosion with experimental data," Journal of Loss Prevention in the Process Industries, vol. 26, no. 6, pp. 1549-1557, 2013.

[11] P. A. Cubbage and W. A. Simmonds, "An investigation of explosion relief for industrial drying ovens, I-Top reliefs in box ovens," Proceedings of the Institution of Mechanical Engineers, vol. 105, pp. 470-475, 1955. 
[12] W. A. Simmonds and P. A. Cubbage, "The design of explosion reliefs for industrial drying ovens," in Proceedings of the First Symposium on Chemical Process Hazards, p. 69, 1960.

[13] M. Dragosavic, "Structural measures against natural-gas explosions in high-rise blocks of flats," Heron, vol. 19, no. 4, pp. 5-51, 1973.

[14] D. J. Rasbash, D. D. Drysdale, and D. Kemp, "Design of an explosion relief system for a building handing liquefied fuel gases," in Proceedings of the I. Chem. E. Symposium Series no. 47 Symposium on Process Industry Hazard, p. 145, 1976.

[15] A. Huser, T. Foyn, and M. Skottene, "A CFD based approach to the correlation of maximum explosion overpressure to process plant parameters," Journal of Loss Prevention in the Process Industries, vol. 22, no. 3, pp. 324-331, 2009.

[16] J. Karnesky, P. Chatterjee, F. Tamanini, and S. Dorofeev, "An application of 3D gasdynamic modeling for the prediction of overpressures in vented enclosures," Journal of Loss Prevention in the Process Industries, vol. 20, no. 4-6, pp. 447-454, 2007.

[17] H. H. Pedersen, G. Tomlin, P. Middha, H. N. Phylaktou, and G. E. Andrews, "Modelling large-scale vented gas explosions in a twin-compartment enclosure," Journal of Loss Prevention in the Process Industries, vol. 26, no. 6, pp. 1604-1615, 2013.

[18] NFPA 68, Standard on explosion protection by deflagration venting, National Fire Protection Association, Quincy, Massachusetts, Mass, USA, 2013.

[19] EN 14494, Gas explosion venting protective systems, European Committee for Standardization, Brussels, Belgium, 2007.

[20] B. H. Hjertager, T. Solberg, and K. O. Nymoen, "Computer modelling of gas explosion propagation in offshore modules," Journal of Loss Prevention in the Process Industries, vol. 5, no. 3, pp. 165-174, 1992.

[21] GexCon, FLACS v9.1 user’s manual, 2011.

[22] K. N. Bray, "Studies of the turbulent burning velocity," Proceedings of the Royal Society of London, vol. 431, no. 1882, pp. 315-335, 1990.

[23] B. J. Arntzen, Modelling of turbulence and combustion for simulation of gas explosions in complex geometries [Ph.D thesis], 1998.

[24] B. H. Hjertager, K. Fuhre, and M. Bjørkhaug, Spherical gas explosion experiments in a high-density obstructed $27 \mathrm{~m}^{3}$ corner, Report on large-scale experiments performed at Sundsli, 1988.

[25] X. Rocourt, S. Awamat, I. Sochet, and S. Jallais, "Vented hydrogen-air deflagration in a small enclosed volume," International Journal of Hydrogen Energy, vol. 39, no. 35, pp. 2046220466, 2014.

[26] S. B. Dorofeev, "Flame acceleration and explosion safety applications," Proceedings of the Combustion Institute, vol. 33, no. 2, pp. 2161-2175, 2011.

[27] C. R. Bauwens, J. Chaffee, and S. B. Dorofeev, "Experimental and numerical study of hydrogen-air deflagrations in a vented enclosure," in Proceedings of the 6th International Symposium on Hazards, Prevention and Mitigation of Industrial Explosions, 2008.

[28] G. Taguchi, Introduction to Quality Engineering, Designing Quality into Products and Process, ARRB Group Limited, Vermont South, Australia, 1986.

[29] J. L. Deng, "Introduction to grey system theory," The Journal of Grey System, vol. 1, no. 1, pp. 1-24, 1989.

[30] W. Zuo, E. Jiaqiang, X. Liu, Q. Peng, Y. Deng, and H. Zhu, "Orthogonal Experimental Design and Fuzzy Grey Relational
Analysis for emitter efficiency of the micro-cylindrical combustor with a step," Applied Thermal Engineering, vol. 103, pp. 945951, 2016.

[31] Z. Wang, T. Lei, X. Chang et al., "Optimization of a biomass briquette fuel system based on grey relational analysis and analytic hierarchy process: a study using cornstalks in China," Applied Energy, vol. 157, pp. 523-532, 2015.

[32] A. Kadier, P. Abdeshahian, Y. Simayi, M. Ismail, A. A. Hamid, and M. S. Kalil, "Grey relational analysis for comparative assessment of different cathode materials in microbial electrolysis cells," Energy, vol. 90, pp. 1556-1562, 2015.

[33] X. P. Xiao, L. C. Xie, and D. R. Huang, "A modified computation method of grey correlation degree and its application," Application of Statistics and Management, vol. 14, no. 5, pp. 27-30, 1995. 


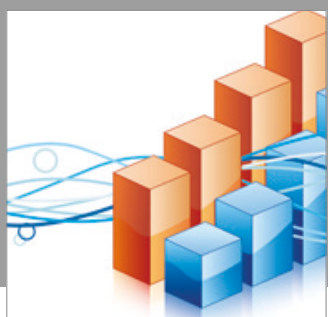

Advances in

Operations Research

vatersals

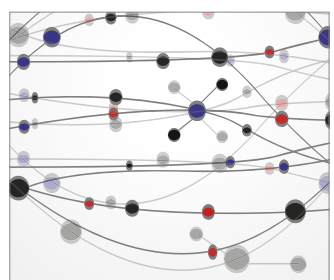

\section{The Scientific} World Journal
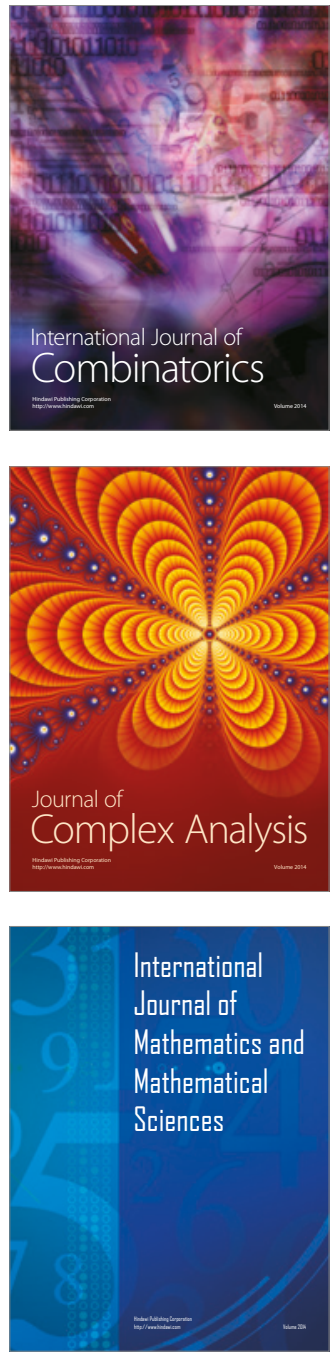
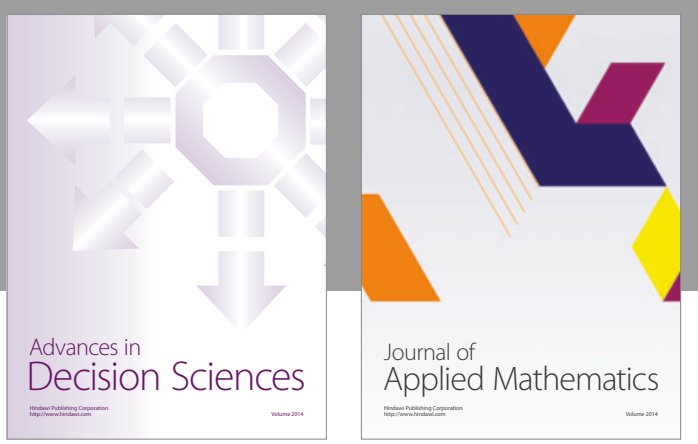

Algebra

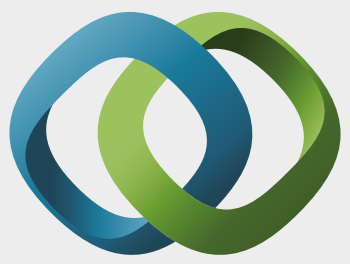

\section{Hindawi}

Submit your manuscripts at

https://www.hindawi.com
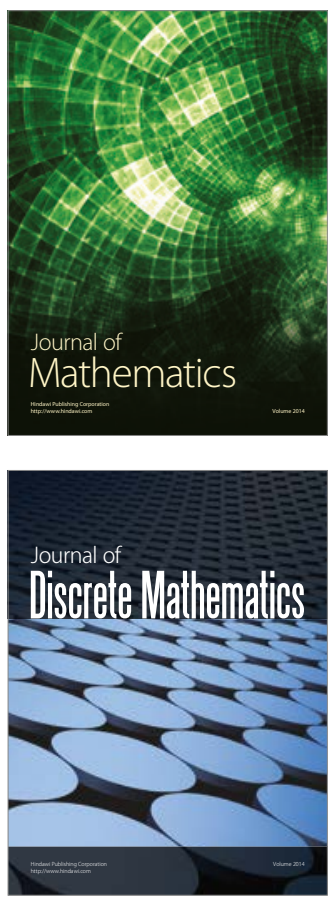

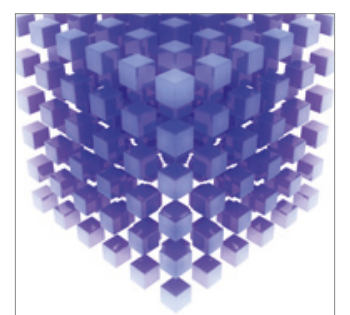

Mathematical Problems in Engineering
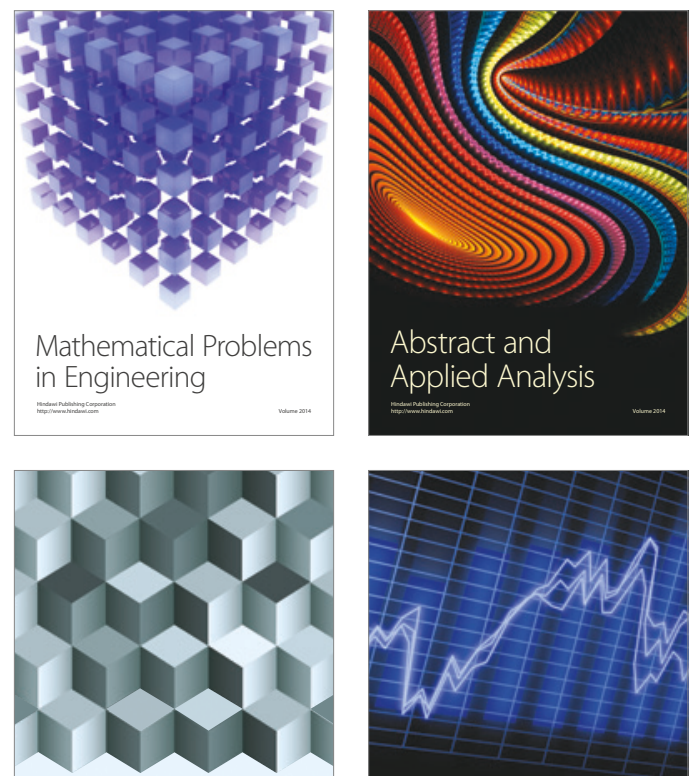

Journal of

Function Spaces

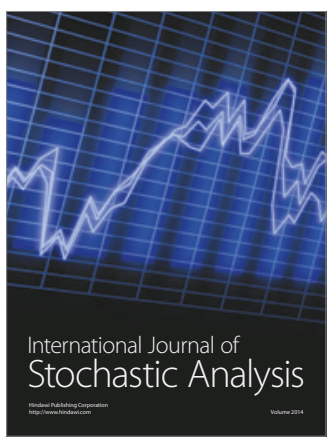

Probability and Statistics
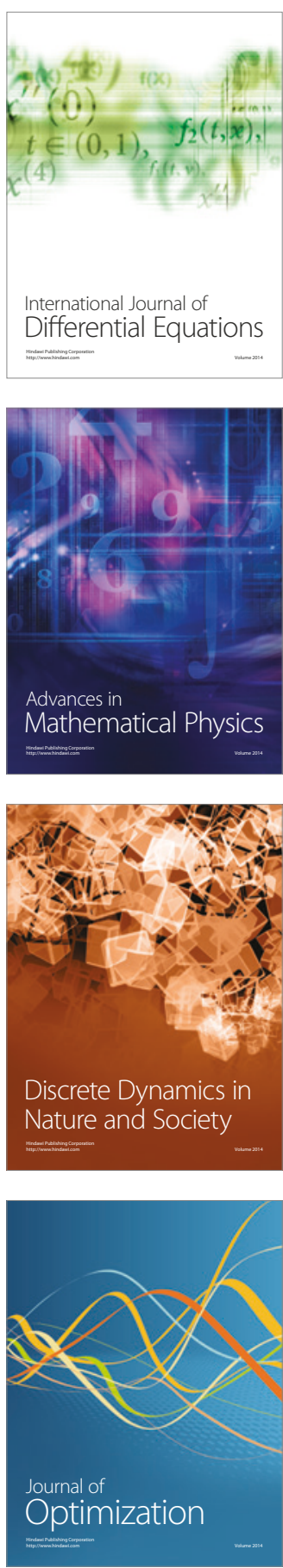